Dieses Dokument ist eine Zweitveröffentlichung (Verlagsversion) /

This is a self-archiving document (published version)

„Dieser Beitrag ist mit Zustimmung des Rechteinhabers aufgrund einer (DFG-geförderten) Allianzbzw. Nationallizenz frei zugänglich."

This publication is openly accessible with the permission of the copyright owner. The permission is granted within a nationwide license, supported by the German Research Foundation (abbr. in German DFG).

https://www.nationallizenzen.de
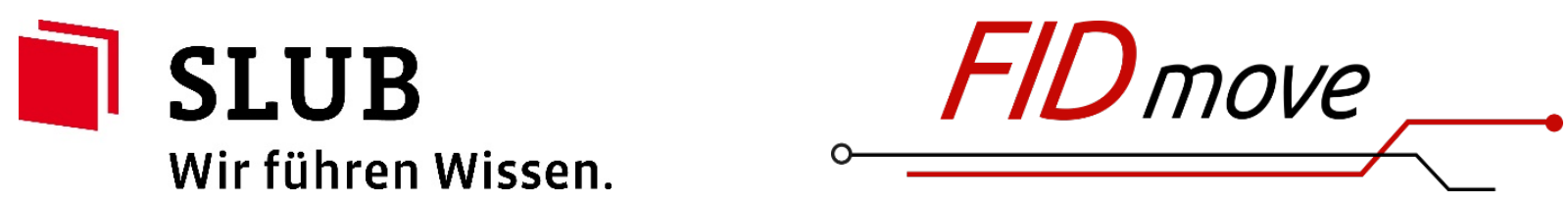


\title{
Thermodynamics and charge exchange of the new BMW six-cylinder engine
}

\author{
E Otto ${ }^{1}, \mathbf{S}$ Rubbert ${ }^{1 *}$ and $\mathbf{J}$ Borrmeister ${ }^{2}$ \\ ${ }^{1}$ BMW AG, Department EA-36, Munich, Germany \\ ${ }^{2}$ Technische Universität, Dresden, Germany
}

\begin{abstract}
The BMW in-line six-cylinder engine has been modified and introduced to production in the new BMW 3 Series model. Its major features include variable intake and exhaust camshaft timing, a new induction system with resonance charging, a turbulence-generating system in the intake ports and a new exhaust system with two closed-loop, coupled catalysts integrated into the exhaust manifold. The cam timing of both camshafts can be adjusted continuously within a range of $40^{\circ} \mathrm{crank}$ angle (CA) for the inlet cams and $25^{\circ} \mathrm{CA}$ for the exhaust cams. The turbulence-generating system supplies combustion air to the engine during part load operation and produces the necessary charge motion to run the engine with greater valve overlap at low loads and speeds. Its combination with variable camshaft timing results in lower fuel consumption and exhaust emissions that meet the LEV emission standard. In addition, the variable cam timing raises the torque curve of the unthrottled engine, particularly at low engine speed. The maximum values for torque and power output are unchanged, but maximum torque is reached $500 \mathrm{r} / \mathrm{min}$ earlier than with the previous engine.
\end{abstract}

Keywords: variable cam timing, turbulence system, resonance intake system, electric throttle

\section{NOTATION}

b.m.e.p. brake mean effective pressure $\left(\mathrm{MN} / \mathrm{m}^{2}\right)$

CA crank angle (deg)

i.m.e.p. indicated mean effective pressure $\left(\mathrm{MN} / \mathrm{m}^{2}\right)$

$\Phi_{\mathrm{I}} \quad$ phase angle inlet (deg CA)

$\Phi_{\mathrm{O}} \quad$ phase angle outlet (deg CA)

\section{THERMODYNAMICS}

Fuel economy and low exhaust emissions were the main targets for further development of the M52 engine introduced in 1995. Increasing the indicated thermal efficiency by means of internal exhaust gas recirculation was one approach in an effort to meet these requirements. Since the preceding model had already been fitted with a variable intake camshaft, which however, only had two settings, it was a logical step to fit the following model with a further developed version offering a greater level of variability [1]. The engineers therefore investigated a continuously adjustable intake and exhaust camshaft system, which while retaining a con-

The MS was received on 29 October 1999 and was accepted after revision for publication on 19 January 2000.

* Corresponding author: BMW AG, Department EA-36, D-80788 Munich, Germany. stant valve opening time would change the valve overlap by means of variable camshaft phase positions. A description of the test engine can be found in the Appendix. Figure 20 shows a cross-section of the test engine.

In the remarks below the camshaft position in relation to the crankshaft is described by the phase angle. This value describes the angle between top dead centre during the exhaust and intake strokes and the crank angle (CA) at maximum valve lift (Fig. 1). At small phase angles the valve overlap area increases and with it the residual gas volume in the cylinder, thus reducing gas exchange losses. At the same time cylinder charge will increase and the effective compression ratio rises. The $p-V$ diagram shows the pumping loops, which are reduced in size at large valve overlap (Fig. 2).

Combustion efficiency will rise as well, owing to the higher effective compression and reduced wall heat losses. Mixture formation is also improved, thanks to higher intake temperatures. Although gas exchange losses continue to drop as the residual gas volume rises, the combustion period is longer and the combustion process becomes unstable. The lowest fuel consumption values are obtained at medium phase angles, where a balance is established between low gas exchange losses and good combustion efficiency.

Figure 3 illustrates specific fuel consumption during part-load operation, according to camshaft phase angle. 


\section{Valve Lift}

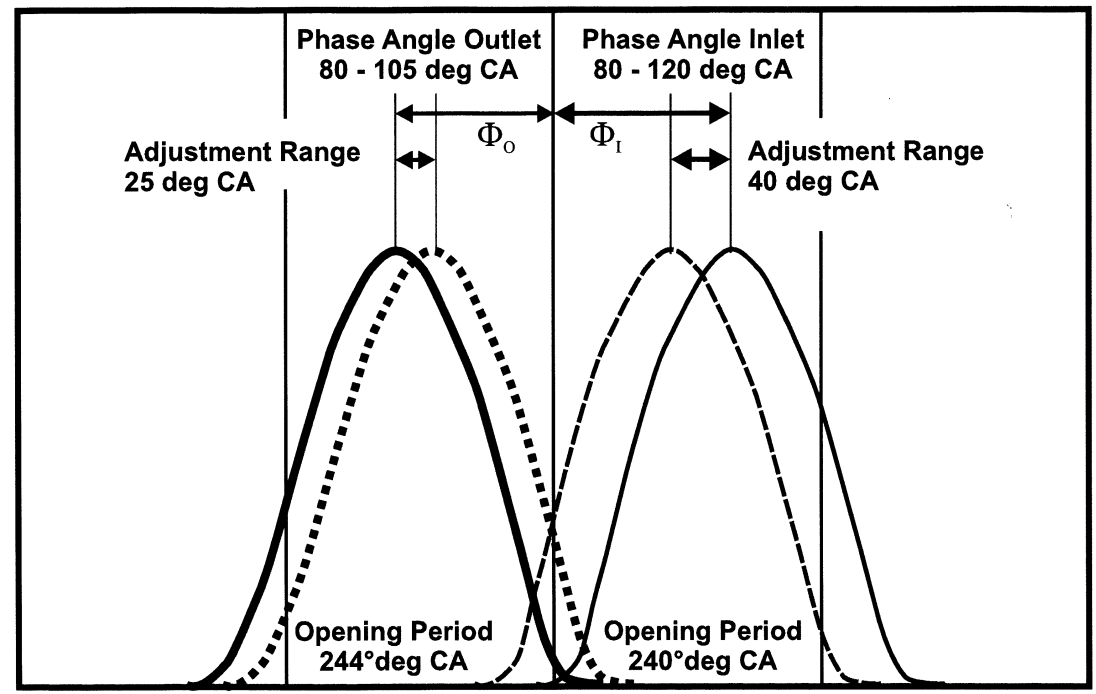

Crank Angle [deg CA]

Fig. 1 Adjustment range of the variable camshaft phasing system

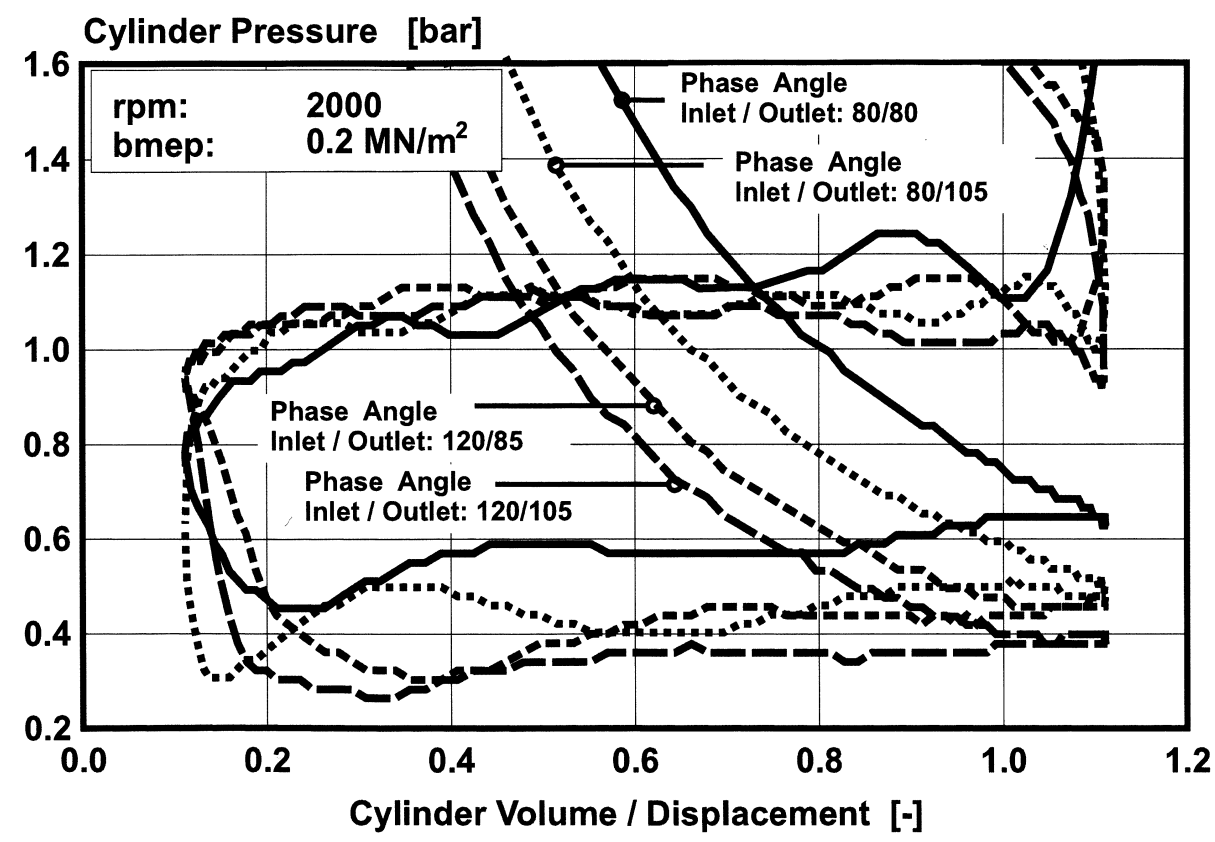

Fig. 2 Influence of camshaft phase angles on gas exchange process

The consumption value at an intake phase angle of $110^{\circ}$ and an exhaust phase angle of $105^{\circ}$ was selected as the reference basis, since with this combination the engine was capable of running with fixed timing. In relation to this setting, greater valve overlap results in a drop in fuel consumption of approximately 3 per cent, but an even greater valve overlap will lead to distinctly unfavourable fuel consumption values. Figure 4 shows how the gas exchange losses are at a minimum at the greatest valve overlap. At optimal fuel consumption the gas exchange losses can be reduced by about 3 per cent compared with the reference case. Figure 5 shows the indicated thermal efficiency for the combustion cycle. The highest combustion efficiency is obtained with the combination of $105^{\circ}$ intake phase angle and $100^{\circ}$ exhaust phase angle. Lower valve overlap results in only a minor drop in efficiency, whereas greater valve overlap keeps efficiency at a constant level initially before it drops by as much as 12 per cent at even smaller phase angles.

Valve overlap also has an influence on exhaust emissions. At small exhaust phase angles hydrocarbon (HC) emissions are reduced to a minimum, since the late 


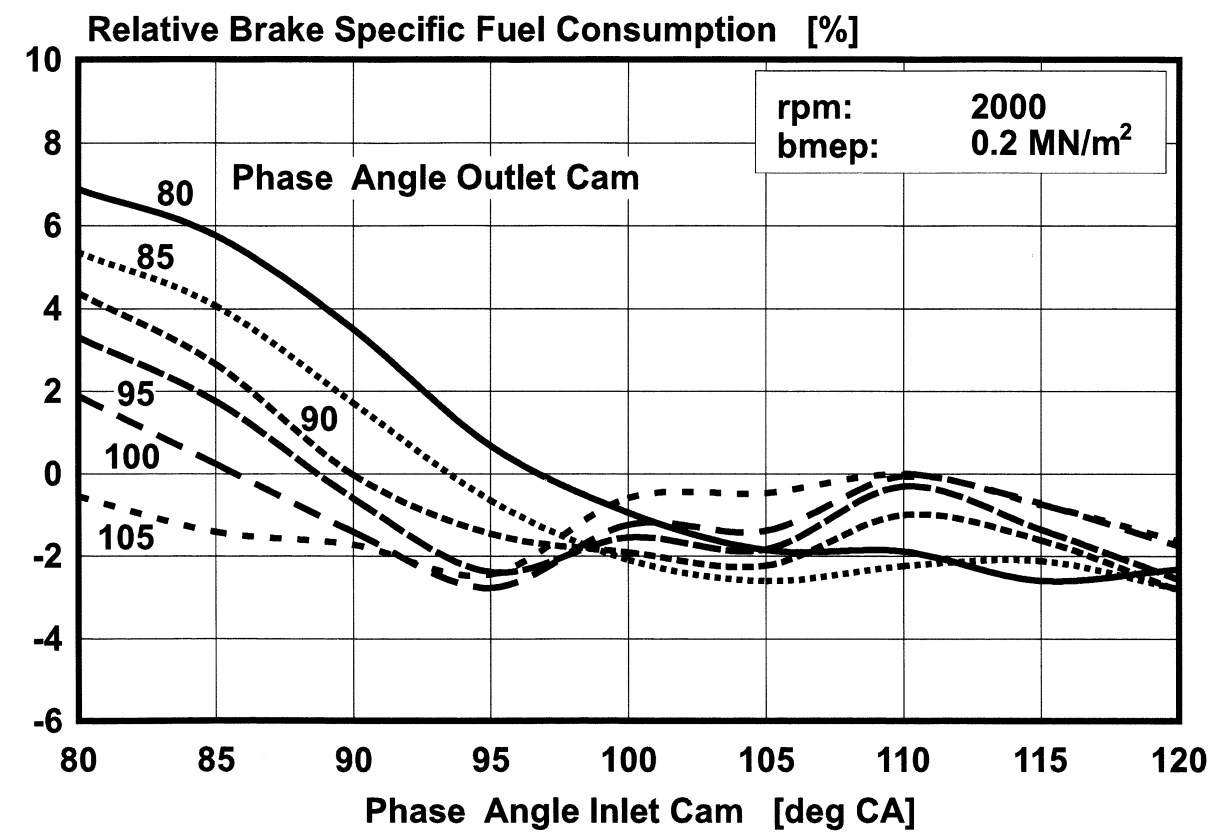

Fig. 3 Influence of camshaft phase angles on brake-specific fuel consumption

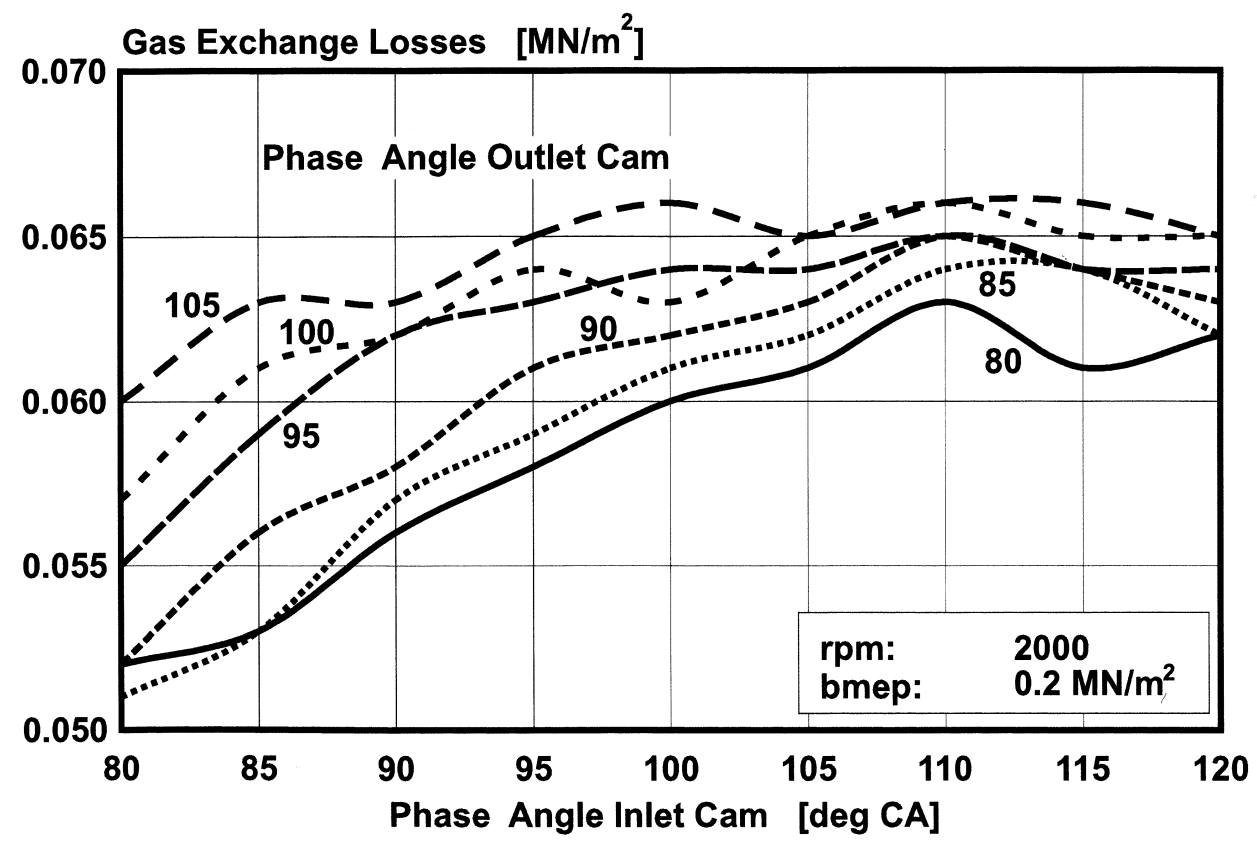

Fig. 4 Influence of camshaft phase angles on gas exchange losses

closing of the exhaust valve causes the emission last ejected to be drawn in again. These emissions contain high $\mathrm{HC}$ concentrations. In addition, the longer expansion phase, because of the late opening of the exhaust valve, gives rise to more intensive secondary reactions. Higher intake temperatures are another cause of reduced $\mathrm{HC}$ emissions, owing to improved mixture formation and a smaller quench zone in the combustion chamber. Also, reduction in the inlet phase angle causes the residual gas volume to rise and $\mathrm{HC}$ emissions to increase substantially, since secondary reactions are rendered more difficult. High residual gas volumes result in misfiring and incomplete combustion owing to premature flame extinction, causing $\mathrm{HC}$ emissions to rise disproportionately. Figure 6 illustrates the relevant characteristic map in relation to the reference case of $110^{\circ}$ for the inlet and $105^{\circ}$ for the exhaust camshafts. The combination of small exhaust and large inlet phase 


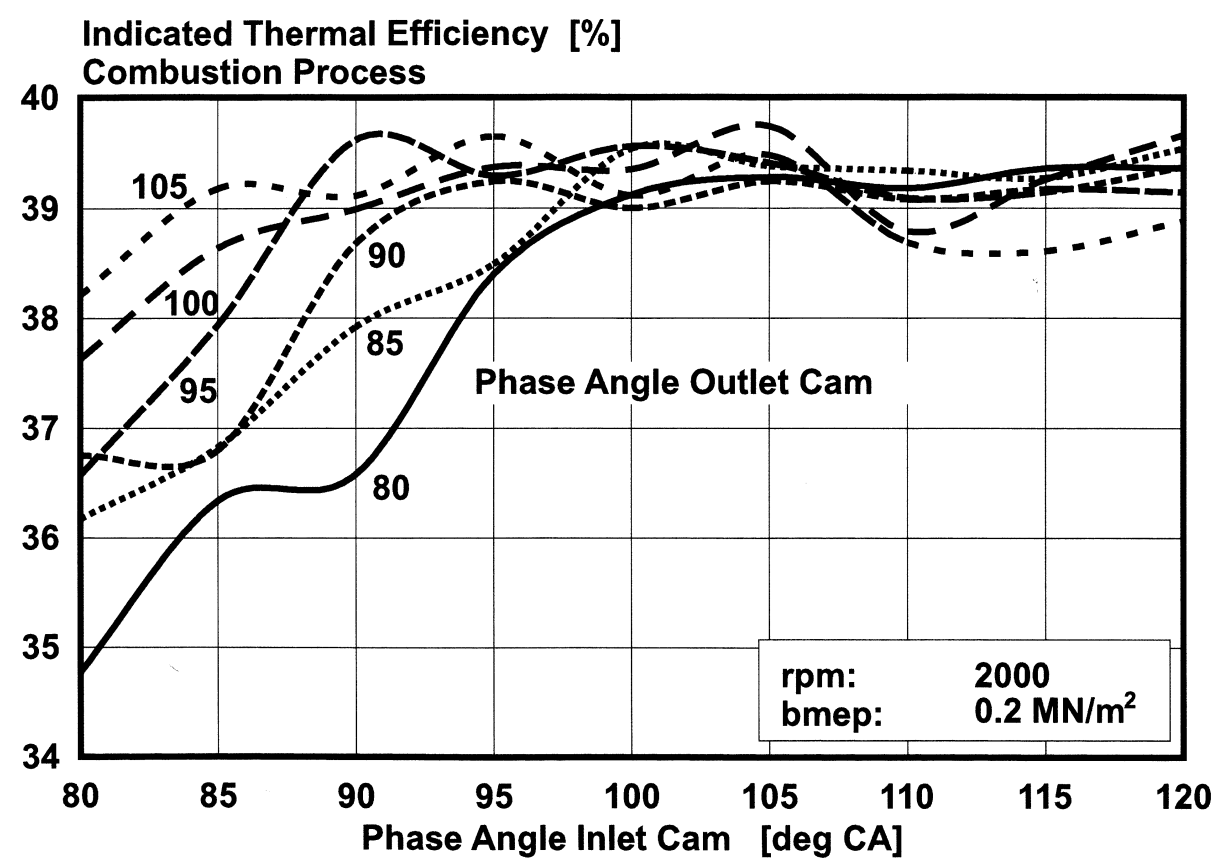

Fig. 5 Influence of camshaft phase angles on indicated thermal efficiency of the combustion process

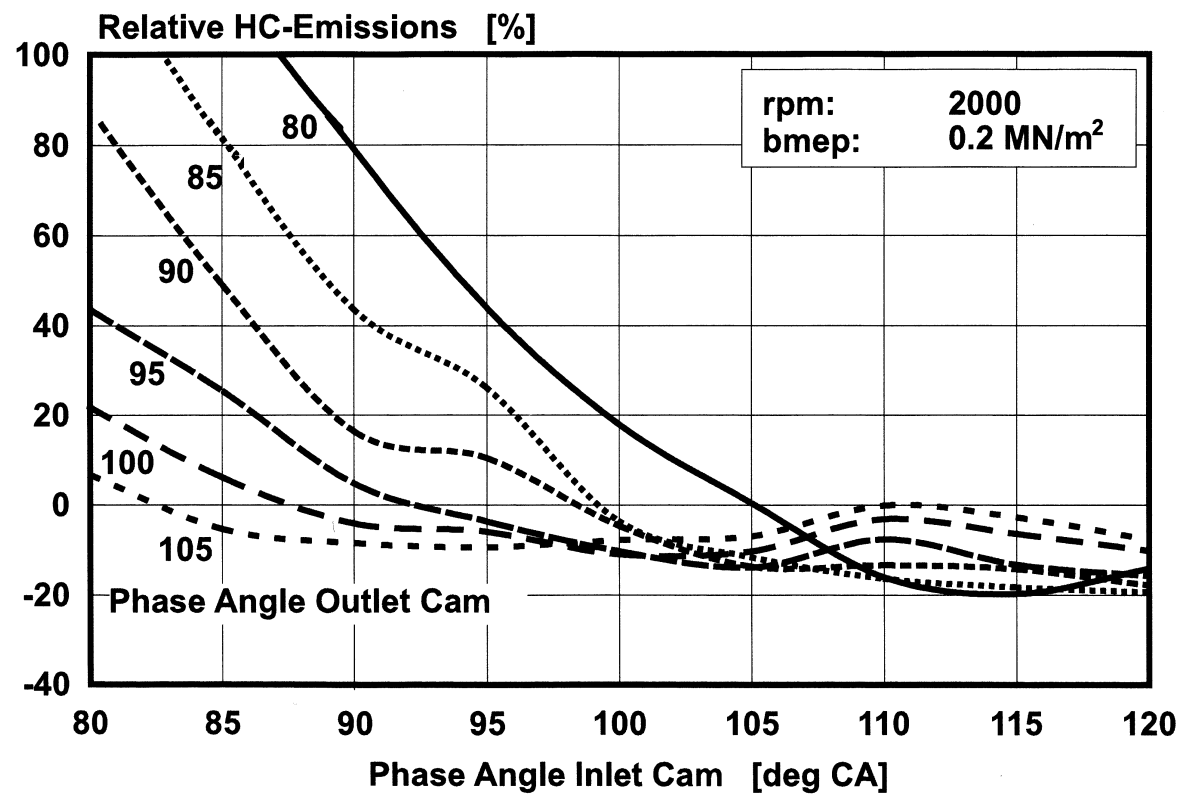

Fig. 6 Influence of camshaft phase angles on HC emissions

angles leads to a reduction in $\mathrm{HC}$ emissions of more than 10 per cent. Greater valve overlaps result in a substantial increase in $\mathrm{HC}$ emissions. $\mathrm{NO}_{x}$ mass emissions exhibit the opposite behaviour, dropping continuously as the residual gas volume increases (Fig. 7). This behaviour is caused by a slower combustion process and a greater cylinder charge. Both mechanisms lead to a lower peak temperature and thus lower $\mathrm{NO}_{x}$ formation. Variation of the phase angles has a greater effect on $\mathrm{NO}_{x}$ than on $\mathrm{HC}$ emissions. At maximum valve overlap, $\mathrm{NO}_{x}$ emissions can be reduced by approximately 90 per cent of the reference level.

Smooth running of the engine is another important factor (Fig. 8). Smooth engine running, plotted in the figure as the standard deviation from the indicated mean effective pressure (i.m.e.p.), becomes unfavourable with increasing residual gas volume, thus limiting the range of phase angle settings. For an application suitable for series production, a smooth-running limit value of 0.1 bar is considered desirable in this operating mode. On 


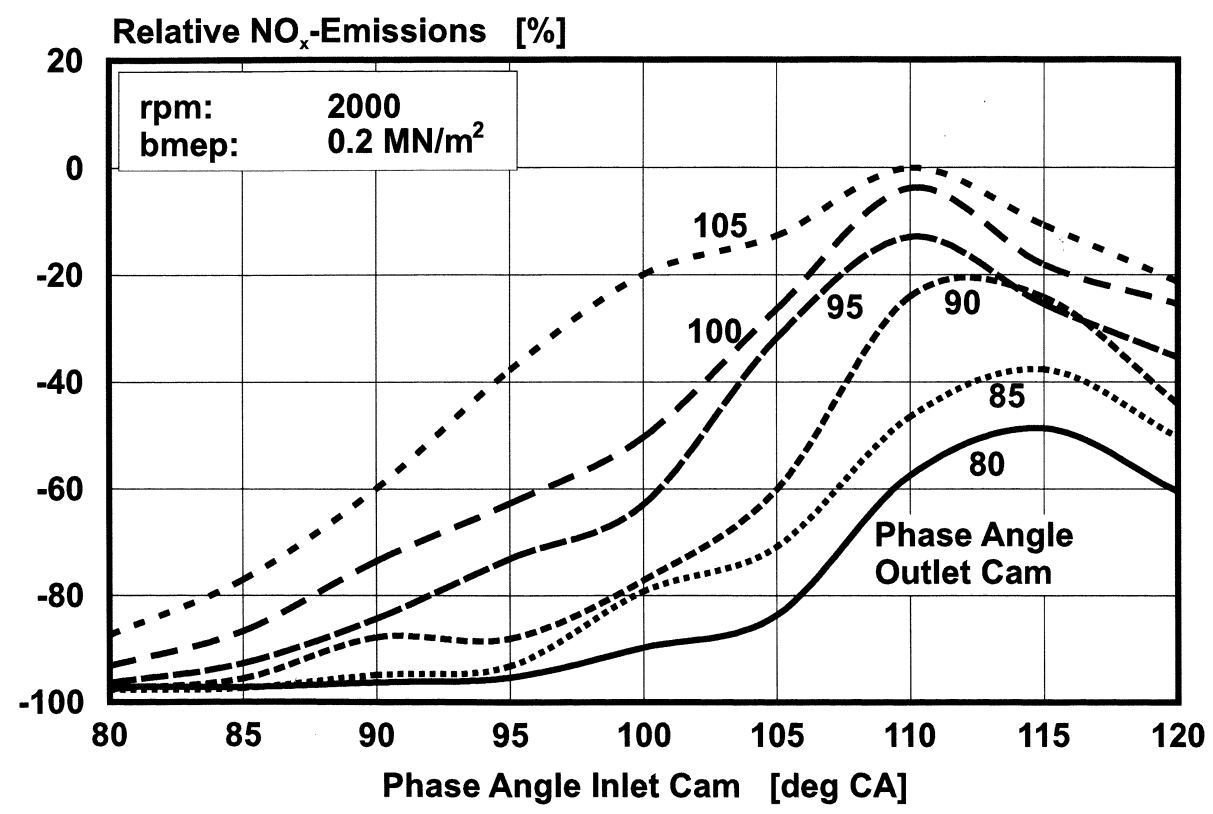

Fig. 7 Influence of camshaft phase angles on $\mathrm{NO}_{x}$ emissions

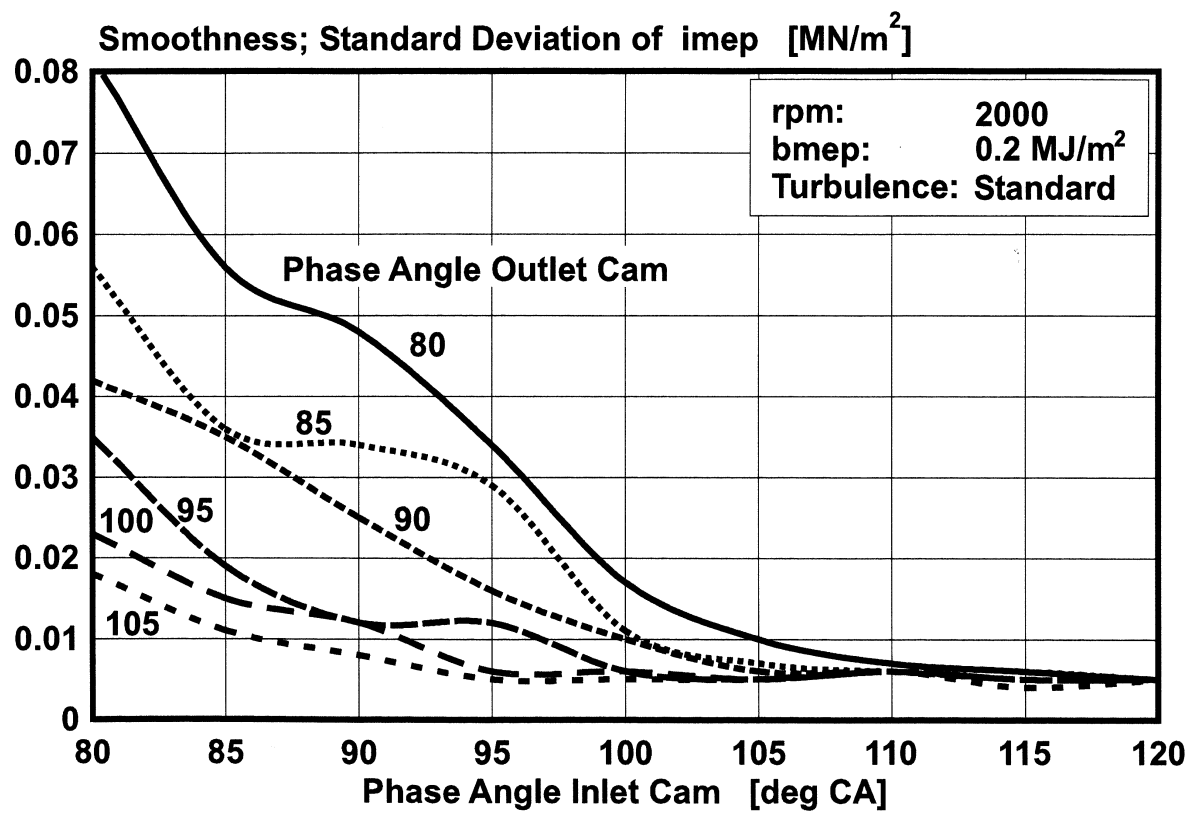

Fig. 8 Influence of camshaft phase angles on engine smoothness (standard deviation of i.m.e.p.) without turbulence system

the basis of this smooth-running criterion, approximately one-third of the possible characteristic map area cannot be used. In addition, the phase angle combination with the lowest fuel consumption value $\left(95^{\circ} \mathrm{CA}\right.$ inlet, $100^{\circ} \mathrm{CA}$ exhaust) proves to be situated at the limit of the smooth-running tolerance range; hence slightest changes in the setting or in ambient conditions affect the smooth-running criterion.

The present characteristic map was recorded at medium part-load operation $[n=2000 \mathrm{r} / \mathrm{min}$; brake mean effective pressure (b.m.e.p.) $=0.2$ bar]. The characteristic fuel consumption map shows that in general internal exhaust gas recirculation permits the desired rise in efficiency by means of variable inlet and exhaust phase angles. However, this causes smooth engine running to deteriorate and also leads to a substantial rise in the ignition advance angle. This makes safe application on a volume production engine very difficult, since even slight changes in ambient conditions and standard tolerances will lead to unfavourable results. At low engine loads 
and engine speeds the residual gas volume is higher owing to increased throttling, and the chances of reducing fuel consumption by means of internal exhaust gas recirculation are very low. For this reason the test engine was fitted with a turbulence system which helps to stabilize and accelerate the combustion process. The system features an additional intake unit, with separate intake plenum and turbulence nozzles running below the inlet port and ending tangentially at the inlet valve seat ring (Fig. 9). At idle speed and low part load, the engine is supplied with intake air exclusively through the turbulence system. Here the narrow flow cross-sections of the turbulence nozzles result in a very high flow speed and thus in improved mixture formation and more intensive charge movement in the cylinder. Figure 10 shows a combustion analysis plot for the basic engine and for the variant with turbulence system at equal residual gas volume in partial load operation. It is obvious that the turbulence system may lead to a shorter ignition delay phase and combustion time. Figure 11 shows, in comparison with Fig. 8, the smooth-running characteristic map at medium partial load for the basic variant and for the engine featuring the turbulence sys- tem. The turbulence system gives rise to improved smooth running and thus higher residual gas compatibility, so that the smooth running limit value of 0.1 bar within 85 per cent of the phase angle map can be met. On the base engine the acceptable smooth running area is substantially smaller. The ignition angle characteristic map illustrates the lower ignition advance requirement due to the turbulence system (Figs 12 and 13). By changing the phase angle the ignition angle gradient becomes considerably smaller. The turbulence system thus helps the desired increase in stability and application reliability to be obtained.

The variable phase angle also allows a reduction in residual gas volume at low part load and idle speed thanks to non-overlap operation, thus permitting a reduced idle speed and improved idle speed quality. Figure 14 shows a comparison of idle speed ignition hooks between the non-overlap setting and the reference timing as they would be selected for a standard engine layout. The standard layout exhibits considerably poorer smooth running and higher fuel consumption than with non-overlap operation.

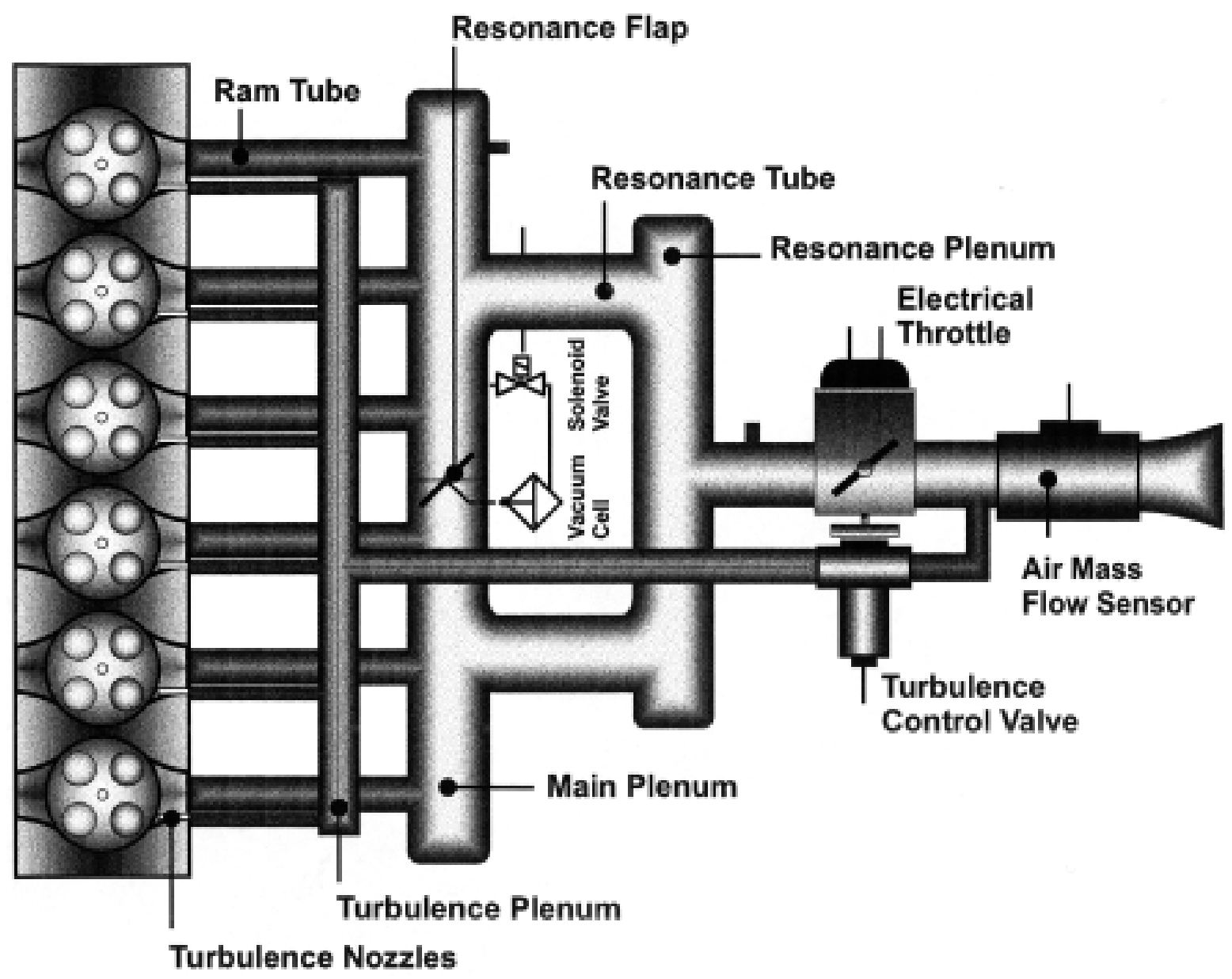

Fig. 9 Induction system 


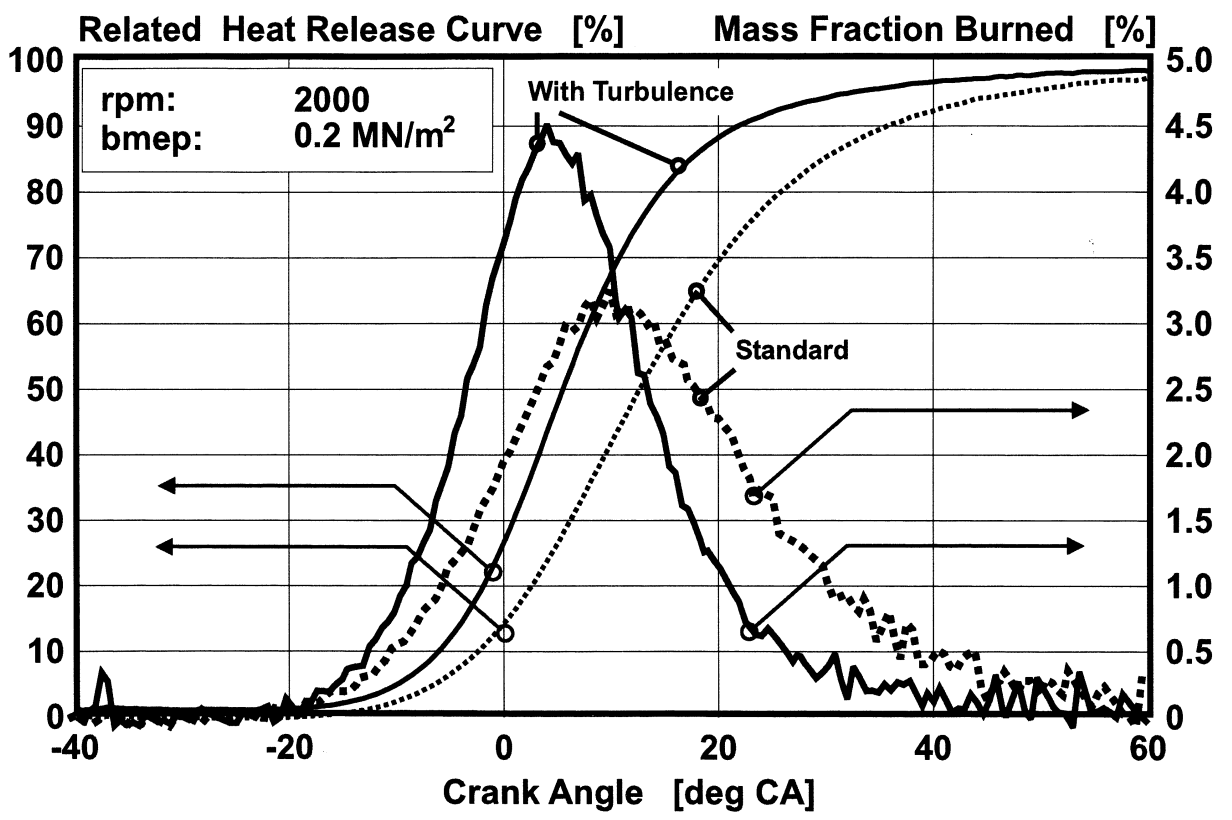

Fig. 10 Influence of the turbulence system on combustion process

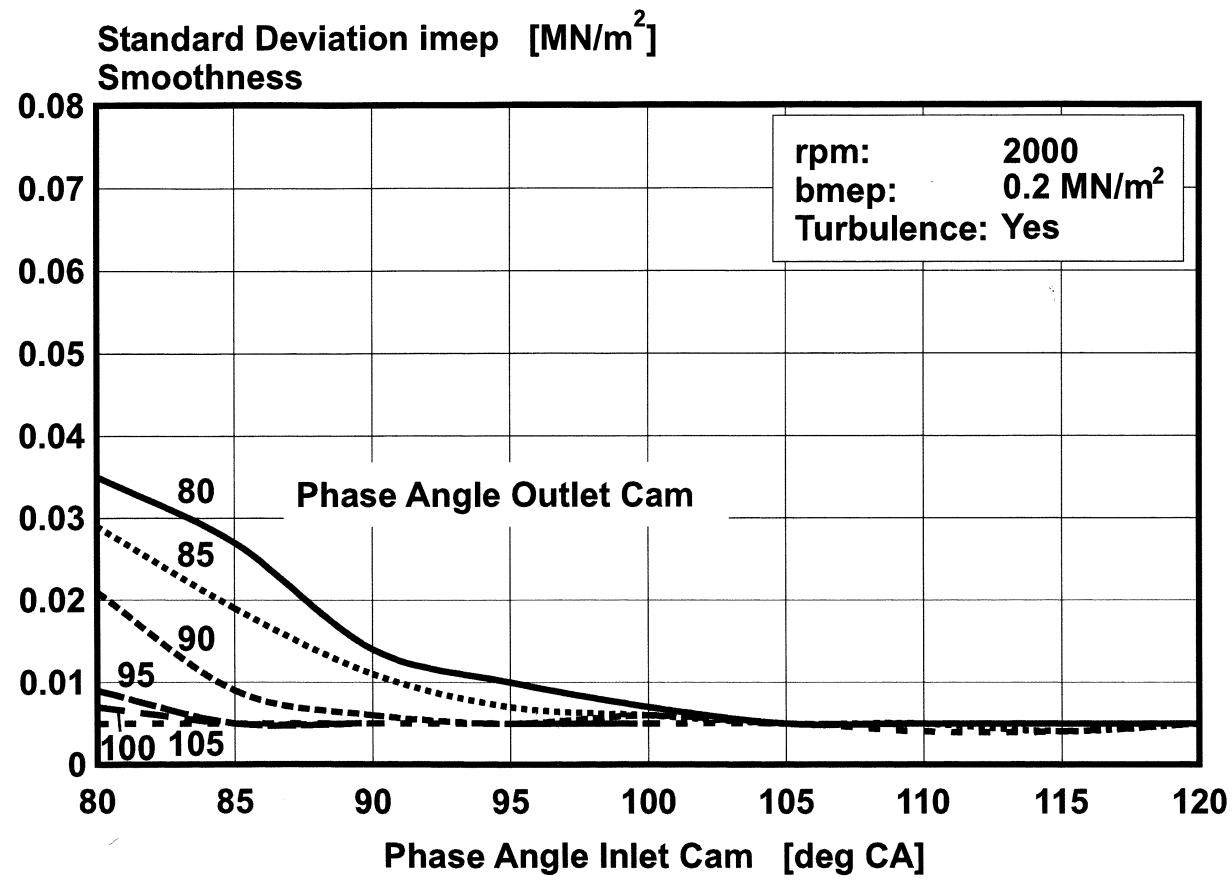

Fig. 11 Influence of camshaft phase angles on smoothness (standard deviation of i.m.e.p.) with turbulence system

\section{CHARGE EXCHANGE PROCESS}

During full-load operation, engine torque can be influenced by variable camshaft phase angles (Fig. 15). In particular in the lower and medium speed ranges, torque is raised by as much as 10 per cent compared with fixed timing settings. This is largely due to the inlet camshaft timing, but torque maximization in the range up to $3500 \mathrm{r} / \mathrm{min}$ also calls for an alteration to the exhaust phase angle. Variable valve timing primarily achieves improved cylinder filling (Fig. 16). The inlet camshaft phase angle exerts a greater influence, since earlier closing of the inlet valve at low speeds will prevent part of the cylinder charge from being pushed back at the 


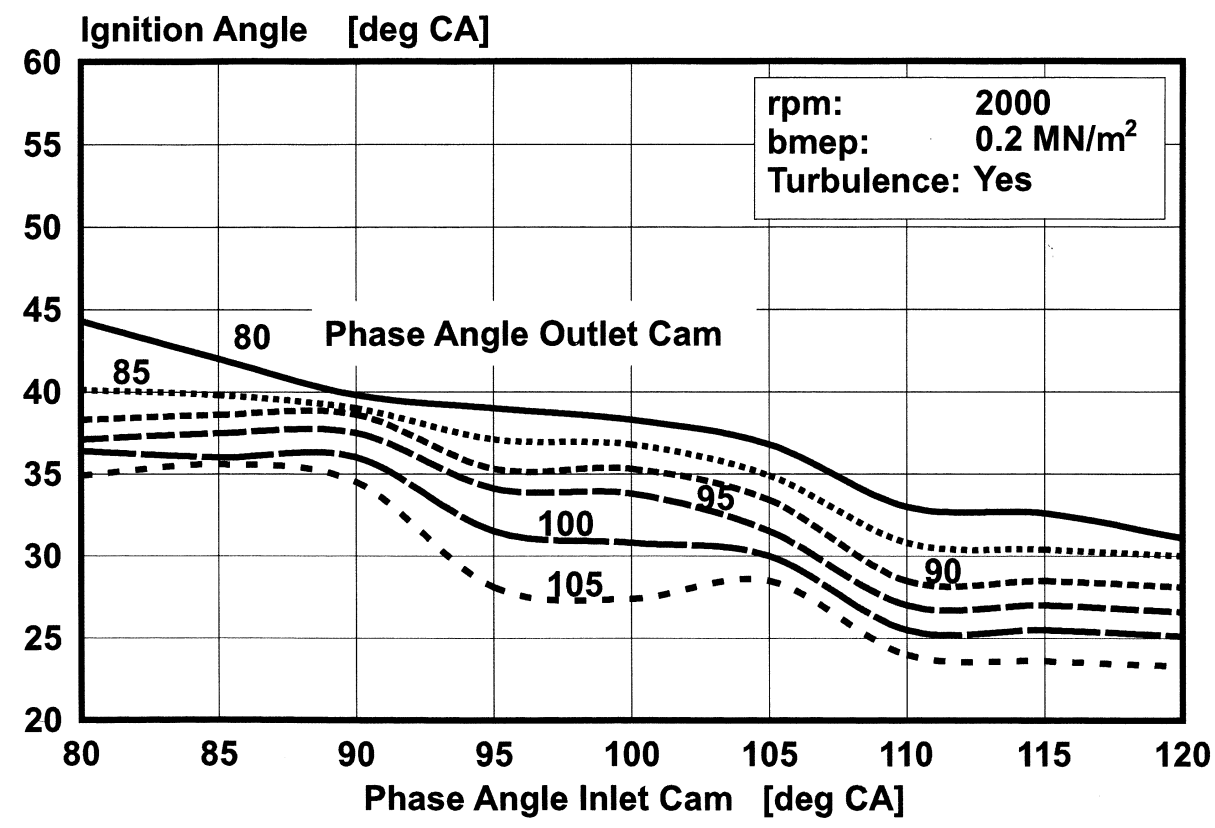

Fig. 12 Influence of the turbulence system on optimized ignition angle (with turbulence)

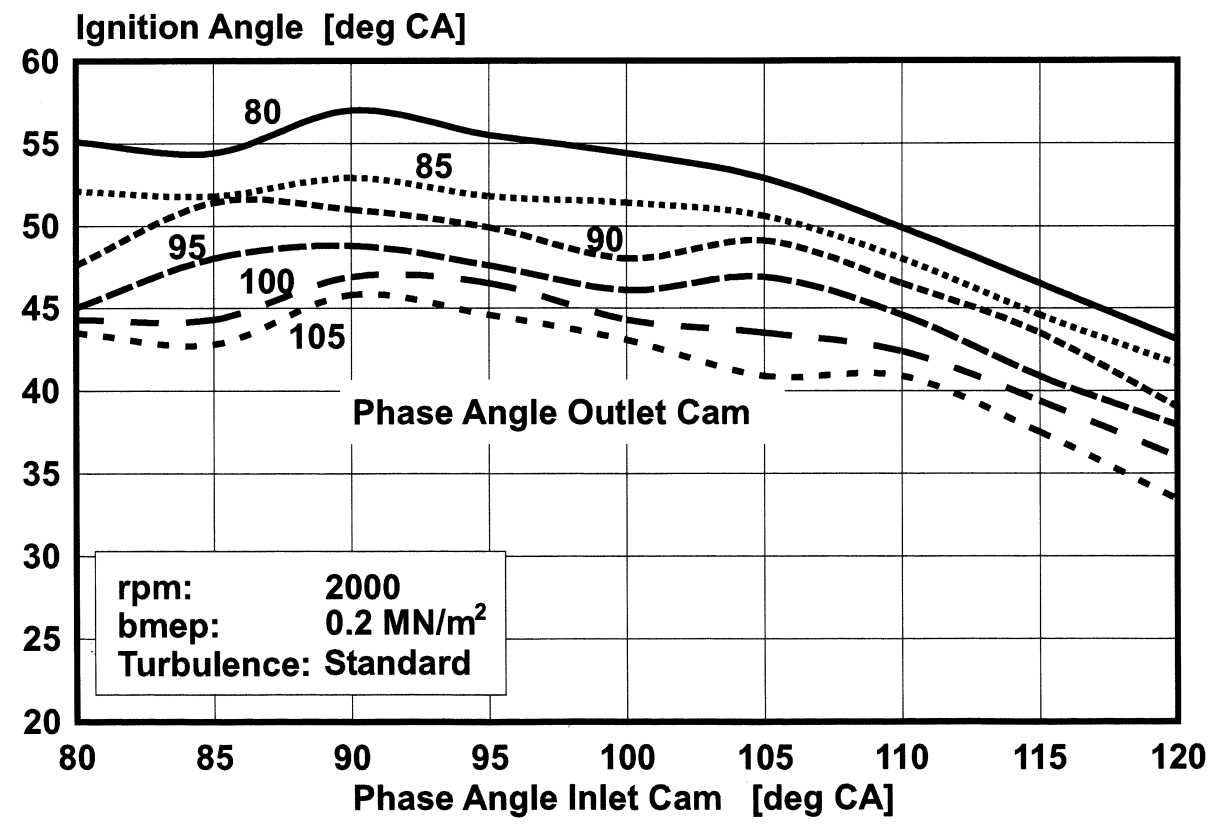

Fig. 13 Influence of the turbulence system on optimized ignition angle (without turbulence)

beginning of the compression phase. At high engine speeds a large inlet phase angle permits late closing of the inlet valve, with the relevant charge boosting effects at the beginning of the compression phase. In the low speed range, varying the exhaust camshaft timing results in more favourable air utilization owing to the large amount of overlap, whereas early opening of the exhaust valve at high speeds will reduce the exhaust pumping work.
In addition to cylinder filling, the camshaft phase angles also have an effect on the knock limit. (Fig. 17). Optimized phase angles permit greater ignition timing advance over the major part of the speed range and thus higher torque. Only in the upper engine speed range above $5000 \mathrm{r} / \mathrm{min}$ do the fixed timing settings permit ignition timing further advanced than with optimized phase angles; this can be ascribed to reduced cylinder filling. 


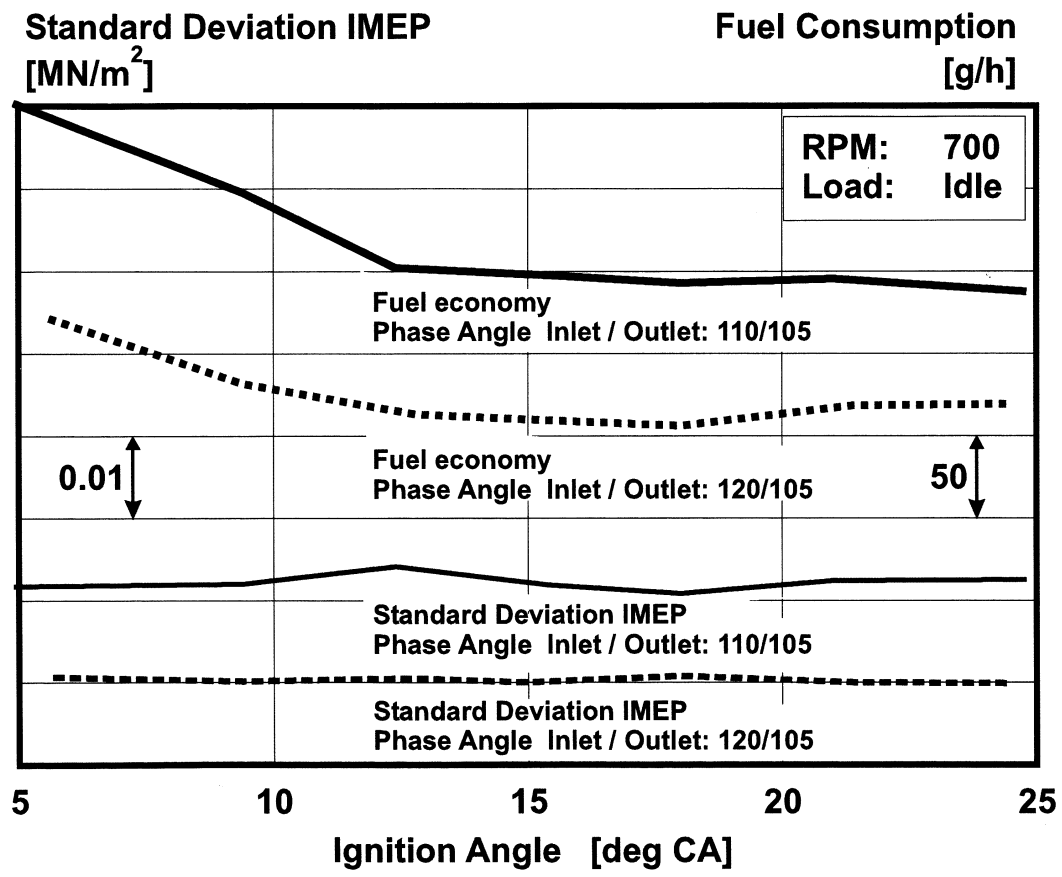

Fig. 14 Influence of camshaft phase angles on behaviour at idle

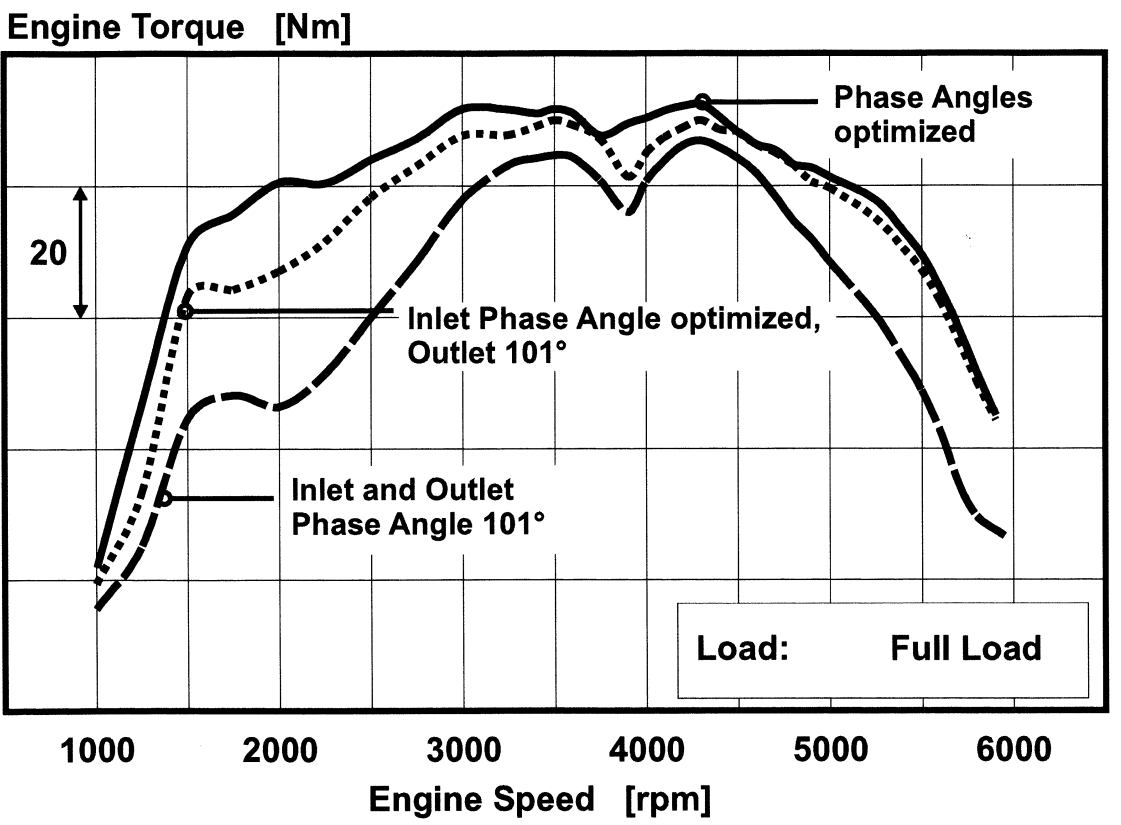

Fig. 15 Influence of camshaft phase angles on engine torque

The air intake system is another building block used to improve the torque curve. Variable factors in the intake system can be used to change its natural frequency and to adapt it to the engine speed. In this way it is possible to obtain a more regular torque curve by means of resonance in the intake system. The schematic structure of the resonance intake system is also shown in Fig. 9. Figure 18 is a comparison of torque curves between the two operating modes of a resonance system and a non-variable intake system. In the lower speed range up to $2000 \mathrm{r} / \mathrm{min}$ no differences can be identified, because only small pressure amplitudes are built up in the resonance pipe. With the divided main plenum the maximum torque is reached at $3200 \mathrm{r} / \mathrm{min}$; it then drops continuously as engine speed increases. The non-divided main plenum causes a sharp drop in torque at $3500 \mathrm{r} / \mathrm{min}$, before maximum torque is reached at $4750 \mathrm{r} / \mathrm{min}$. Between 2000 and $3500 \mathrm{r} / \mathrm{min}$ the non-variable air intake system results 


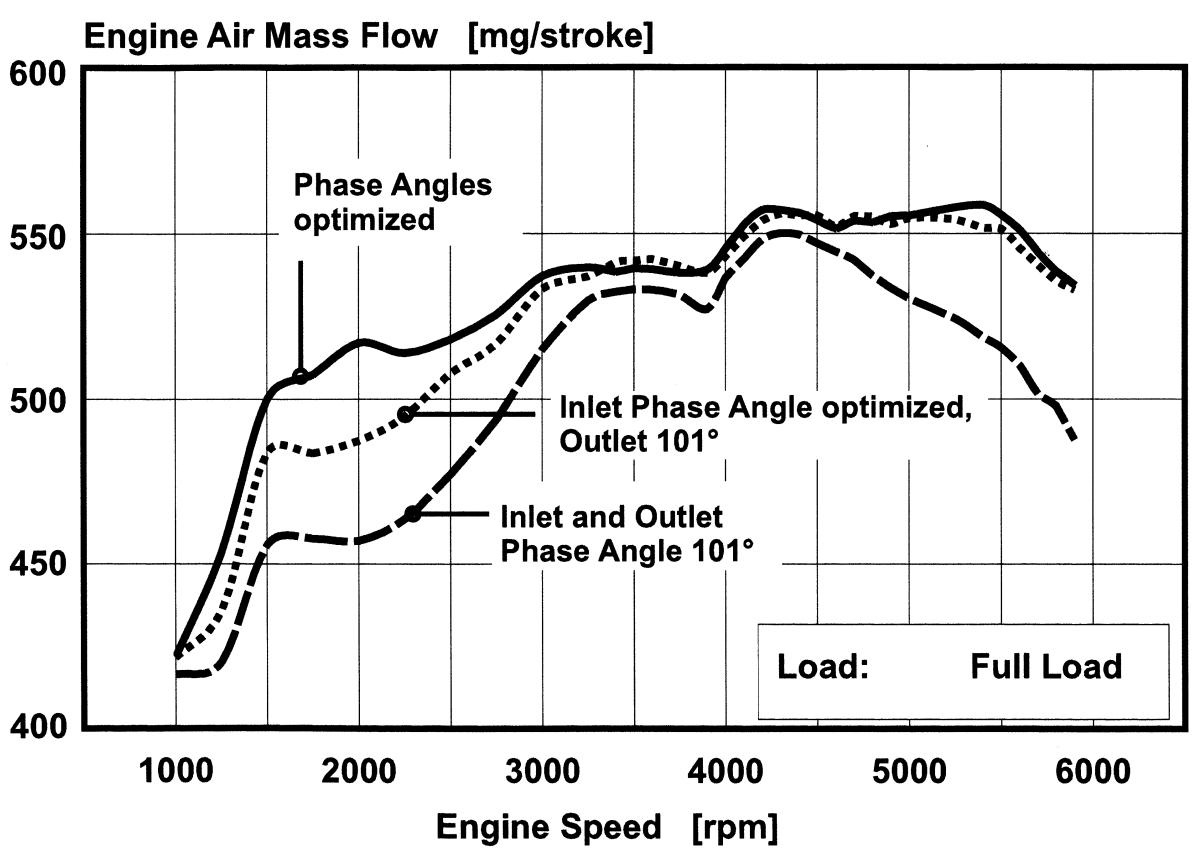

Fig. 16 Influence of camshaft phase angles on air mass flow at full load

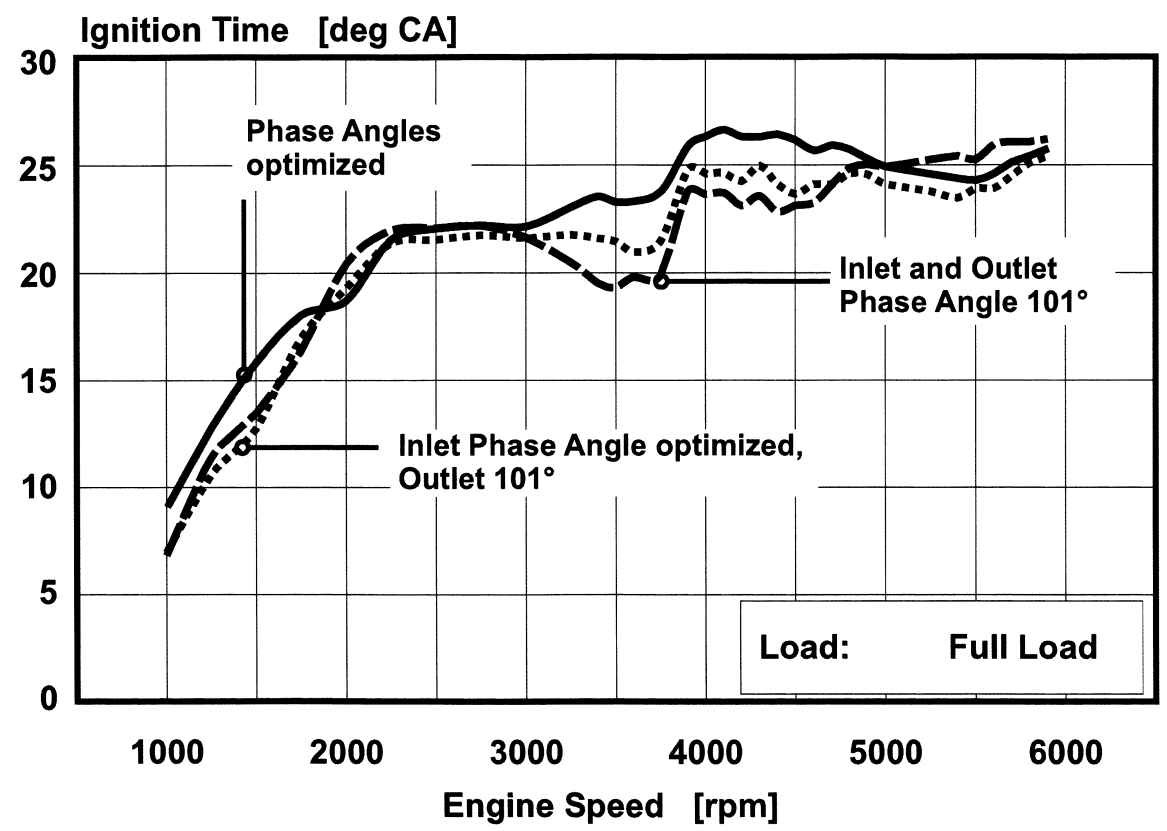

Fig. 17 Influence of camshaft phase angles on ignition angle at full load

in a flat torque curve and a considerable rise in torque above $3750 \mathrm{r} / \mathrm{min}$. Maximum torque is obtained $250 \mathrm{r} / \mathrm{min}$ earlier than with the resonance system in its performance position, and a higher torque output is obtained. Above $5500 \mathrm{r} / \mathrm{min}$, the resonance system causes a lower drop in torque and a higher maximum power output. The resonance system with its change-over option gives rise to a more balanced torque curve and higher power output than the non-variable intake system.

\section{REALIZATION ON THE SERIES PRODUCTION ENGINE}

For the series production engine a resonance intake system with integral turbulence system was developed, based on the concept shown in Fig. 9 [2]. The turbulence system is an independent intake system with separate air plenum. The airflow through the turbulence system is controlled by an idle speed adjuster that is also 


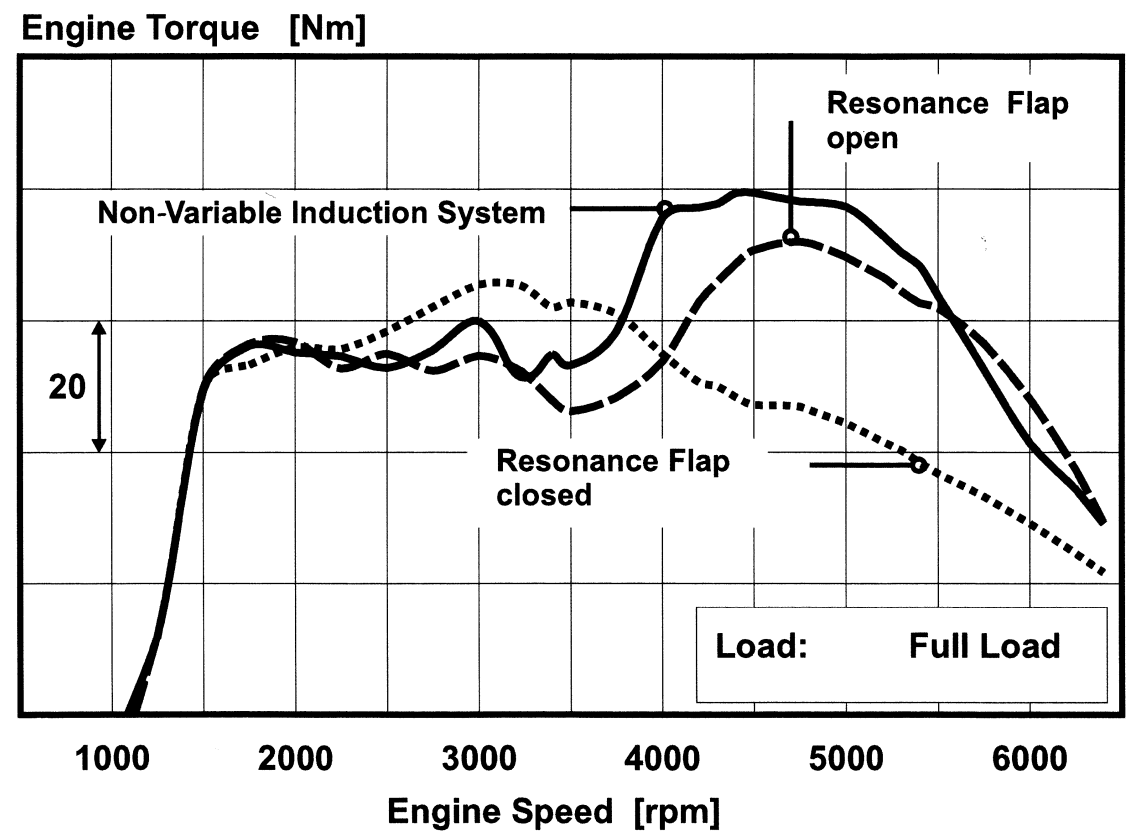

Fig. 18 Influence of the resonance induction system on engine torque

responsible for idle speed filling control. As soon as airflow through the turbulence system cannot be increased any further, the main throttle valve opens and the engine draws in additional combustion air via the main plenum and the resonance pipes. To maximize the airflow at full load, the resonance flap is activated according to engine speed.

The interplay between the throttle and the idle speed adjuster is determined by the requirements of the tur- bulence system and the need for sensitive control at the accelerator pedal. An electric throttle butterfly was used to meet both requirements. It has a progressive opening rate depending on engine speed, load and coolant temperature. Figure 19 illustrates the characteristic map of throttle valve and idle speed adjuster opening in relation to engine load and engine speed. At low engine speeds and loads the main throttle remains closed and the engine is supplied exclusively via the turbulence system.
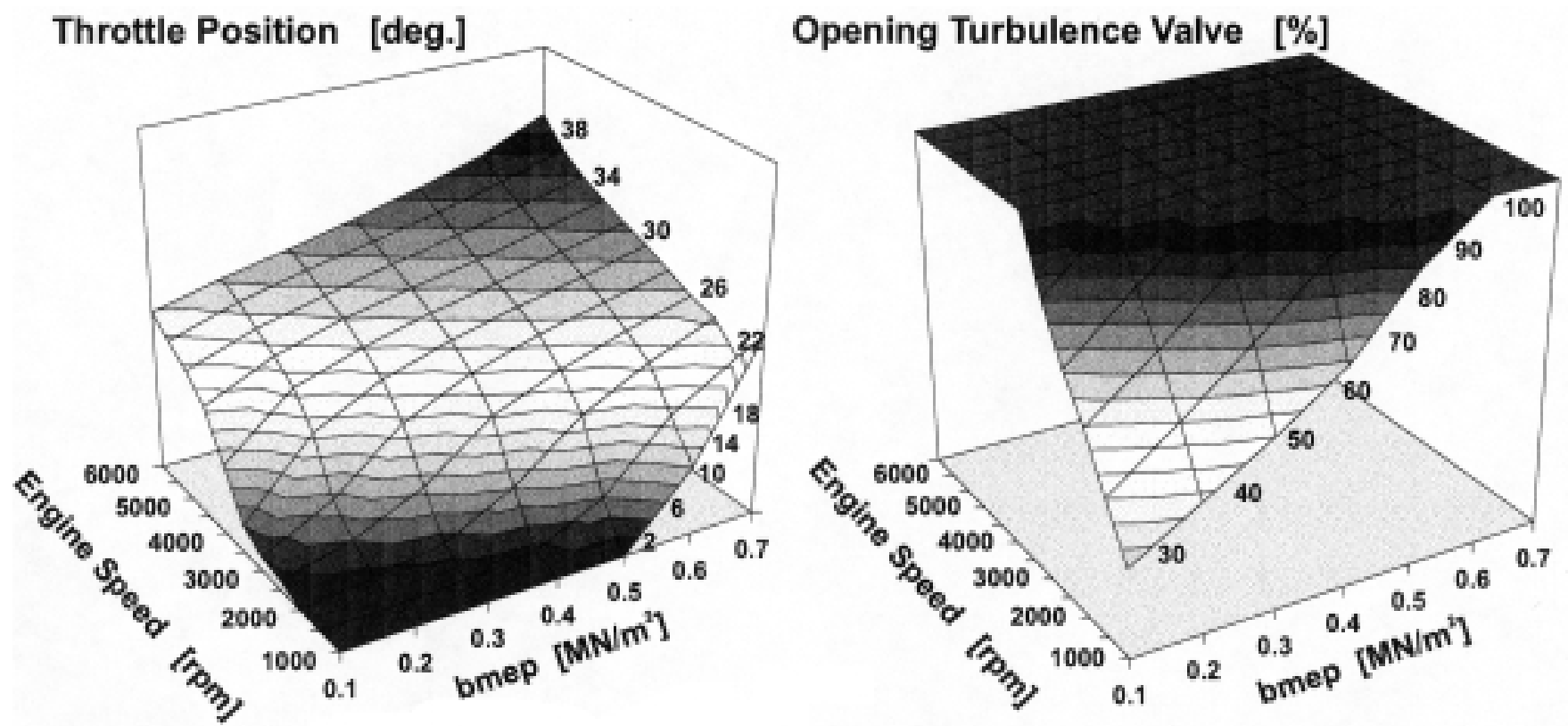

Fig. 19 Opening characteristics of turbulence valve and throttle 


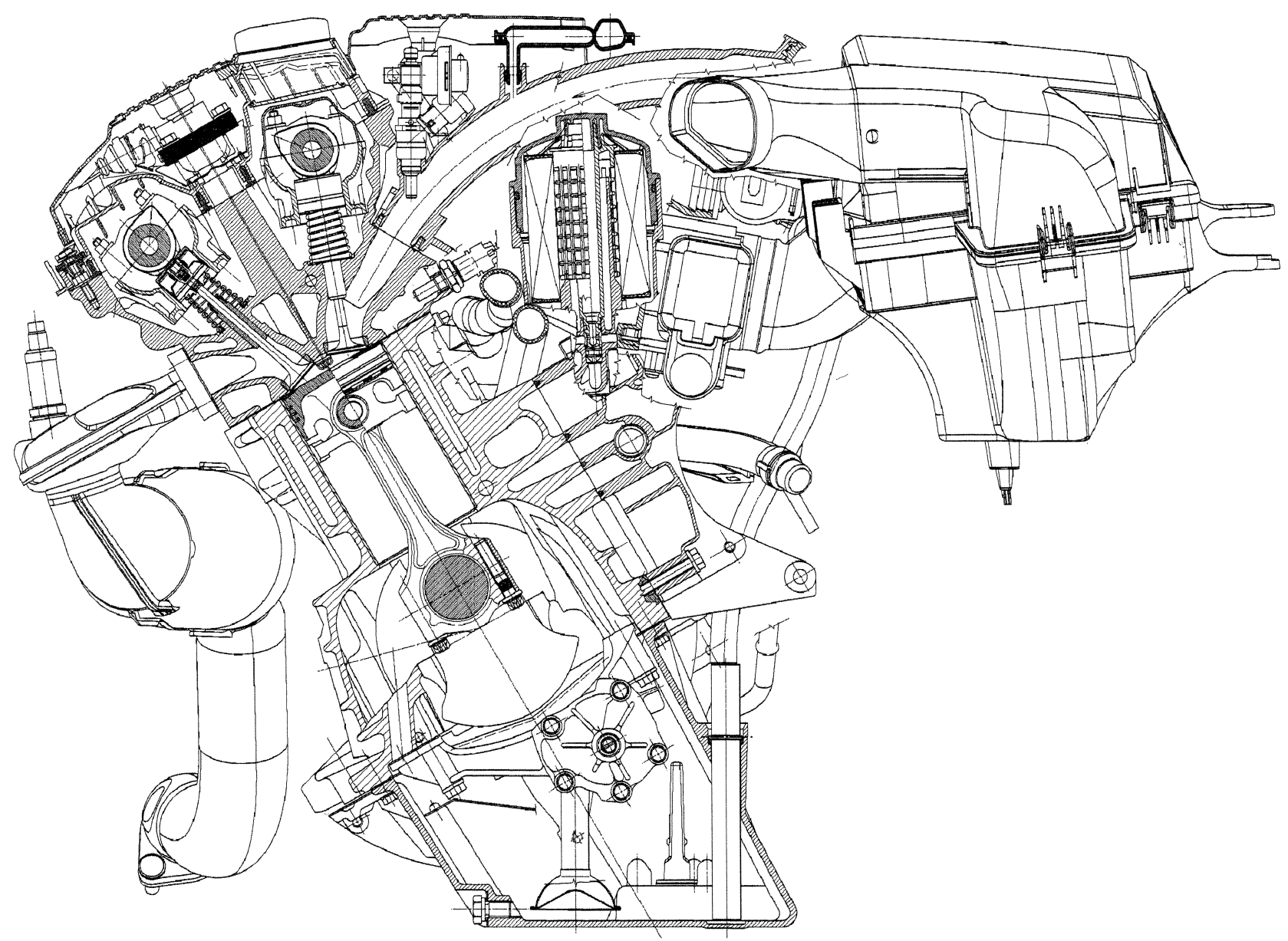

Fig. 20 Cross-section of the test engine

At low speeds and loads the actuator opens relatively quickly and remains fully open as a bypass system for the remainder of the characteristic map. To avoid an erratic transition from the turbulence system's operating range to the main intake system the throttle is activated before the idle speed actuator has opened completely.

\section{SUMMARY}

The new BMW six-cylinder engine is provided with continuously variable inlet and exhaust camshafts in order to reduce fuel consumption and exhaust emissions still further. A turbulence system was introduced to improve combustion stability. In addition, the variable timing permits an increase in full-load torque through improved cylinder filling and reduced knock sensitivity. Furthermore, a resonance air intake system improves cylinder filling in the medium speed range and in the maximum power output area. To control the interplay between the turbulence system and the main intake system in part-load operation, an idle speed actuator was adopted for filling control in the turbulence system and an engine throttle butterfly for the main intake system. The two systems have a progressive action, which depends on engine speed, engine temperature and other parameters.

With this concept it has proved possible to tune all components successfully for the volume production engine and thus to ensure regular and consistent engine behaviour in all the ambient conditions encountered, as well as exploiting the scope offered by variable factors to the greatest practicable extent.

\section{REFERENCES}

1 Bergmann, D., Krause, G., Niggemeyer, H. and Troll, $\mathbf{H}$. Der weiterentwickelte BMW-Sechszylindermotor mit Vierventiltechnik (The further developed BMW six-cylinder engine with four valves per cylinder). Motortechnische $Z$., 1992, 53, 10.

2 Schmidt, G., Flierl, R., Hofmann, R., Liebl, J. and Otto, E. Die neuen BMW 6 Zylindermotoren (The new BMW sixcylinder engines). In Wiener Motorensymposium, 1996. 


\section{APPENDIX}

Table 1 Test engine specification

\begin{tabular}{ll}
\hline Engine type & BMW M52 \\
Number of cylinders & 6 \\
Cylinder arrangement & In line \\
Cooling & Liquid cooled \\
Cycle & Otto cycle \\
Valve train & Double overhead camshaft, four valves per cylinder, \\
& tappets with hydraulic lash adjustment \\
Camshafts & $240^{\circ} \mathrm{CA}$ inlet; $244^{\circ} \mathrm{CA}$ outlet \\
Phase angles & $80^{\circ}-120^{\circ} \mathrm{CA}$ inlet; $80^{\circ}-105^{\circ} \mathrm{CA}$ outlet \\
Compression ratio & 10.0 \\
Combustion chamber & Pent-roof \\
Bore & 84 mm \\
Engine control system & Siemens MS 42 \\
Injection system & Sequential manifold injection
\end{tabular}

